\title{
Testing Epistemic Democracy's Claims for Majority Rule
}

\author{
By William J. Berger ${ }^{1}$ and Adam Sales ${ }^{2}$ \\ (Forthcoming in Politics, Philosophy \& Economics)
}

\begin{abstract}
While epistemic democrats have claimed that majority rule recruits the wisdom of the crowd to identify correct answers to political problems, the conjecture remains abstract. This paper illustrates how majority rule leverages the epistemic capacity of the electorate to practically enhance the instrumental value of elections. To do so we identify a set of sufficient conditions that effect such a majority rule mechanism, even when the decision in question is multidimensional. We then look to the case of sociotropic economic voting in U.S. presidential elections to provide empirical tractability for these conditions. We find that absent such an epistemic capacity a number of presidential elections since 1980 might well have been decided differently. By generating clear conditions for the plausibility of claims made by epistemic democrats, and demonstrating their correspondence to empirical data, this paper strengthens the broader instrumental grounds recommending democracy.
\end{abstract}

Keywords. Democratic theory, epistemic democracy, majority rule, wisdom of the crowd, economic voting, applied political philosophy, Condorcet Jury Theorem

\footnotetext{
${ }^{1}$ University of Pennsylvania, Philosophy, Politics \& Economics Program, zberger@sas.upenn.edu.

${ }^{2}$ UT Austin, College of Education, asales@utexas.edu.
} 


\section{Introduction}

Democratic theory's epistemic turn ought to be exciting for political scientists and political philosophers alike. Beyond the standard endorsements of democracy on procedural, outcome independent grounds, epistemic democracy offers insight into how and why democracy succeeds at getting things "right." Borrowing from Goldman (1999), we'll refer to these sorts of cases as veritistic since they get at the truth. In this way, democratic decision making can be recommended not only for fostering autonomy and fairness, but also on these instrumental grounds. Epistemic democrats have pointed toward wisdom of the crowd results, such as the Condorcet Jury Theorem (CJT) and the Miracle of Aggregation (MA), in order to argue that democracy has a tendency to select the correct candidate or proposal in an election (Landemore (2013); Surowiecki (2004); List and Goodin (2001)). As free and fair elections have become democracy's sine qua non, these results provide good grounds for recommending democracy more broadly.

A nagging worry remains that beyond aggregating beliefs, votes also tally people's divergent values. The examples epistemic democrats frequently use are cases where the correctness criteria are uncontested, such as a guilty verdict or an ox's weight. Political disagreements, however, are commonly understood as disputes of value rather than of fact. Critics argue that the machinery of epistemic democracy cannot plausibly endorse electoral outcomes since issues such as gun control and abortion lack a clear right answer (Anderson (2006); Ingham (2013); Urbinati (2014)).

In this paper we respond to such skepticism and argue that, under certain conditions, democratic elections can be considered veritistic contests, adjudicating which empirical reality obtains, while bracketing the dimensions of value disagreement. The thinking is like this: voters are either better or worse than random at assessing the facts of the matter. Were voters epistemically biased against the candidates that advanced their commitments, the institution would systematically produce 'unwanted effects,' where a voter would be less likely to

obtain her preferred outcome by voting for it. We provide a set of conditions under which voter competence can stifle such unwanted effects.

Since the claim is instrumental in kind-democracy is good in virtue of the outcomes it produces - it is still necessary to demonstrate that the process 
actually reaches the stipulated outcome. Previous treatments of wisdom of the crowd results lack empirical support to ground their relevance (Schwartzberg (2015)). And though casual remarks claim that such a move should in principle be possible (e.g. Page (2007): 256-7; Landemore (2013): 145), there has been no move to meet empirical cases to formal conditions which satisfy the desiderata of epistemic democrats. This paper goes beyond formal theory to provide an empirical case that tracks these conjectures, thereby making good on calls to demonstrate the plausibility of normative theory (e.g. Rehfeld (2010), Wiens (2015)), while also pointing to the broader purchase of arguments made by epistemic democrats to recommend democracy.

Our plan for this paper is first to explain how majority rule yields veritistic outcomes on a single dimension of a decision function, apart from other contested components. In general, no one issue will determine an election's outcome, regardless of the number of voters, their competence, or the extent of their agreement. Nor do the data allow us to parcel out the credence an individual voter has in some dimension of their decision function from the weight that they assign that dimension. However, insofar as voters agree on the desirability of a particular outcome - though they may disagree on the means to achieve it - a candidate's superiority on that issue increases her chances of winning the election, thereby stifling unwanted effects. In Section 2 we specify four jointly sufficient conditions under which this claim holds. What we call the 'majority rule mechanism' shares a core probabilistic structure with wisdom of the crowd results like CJT and MA, albeit with slightly stricter assumptions. These strictures allow us to move beyond unidimensional decisions and consider multidimensional cases that better fit empirical cases. ${ }^{3}$

Section 3 of the paper turns to the case of sociotropic economic voting in U.S. presidential elections to illustrate the empirical traction of the majority rule mechanism. That voters by and large want economic growth provides a ready case where a virtual consensus exists on some value. The contest can then be construed as a vote for the candidate that will in fact maximize that value. We offer a statistical model to provide evidence that voters' beliefs about economic performance actually result in them voting for the better candidate in regard to the economy's performance. This serves as an empirical example of the epistemic quality of the majority rule mechanism. Here, insofar as people substantively agree on a particular value (economic growth), and are in a position to judge that fact (whether the economy has grown), the election can be thought to be

\footnotetext{
${ }^{3}$ While we formally compare the our result to CJT in section 6.2 , we are not merely rearticulating it, as the two results have distinctive assuptions.
} 
biased in favor of the "better" candidate in this particular regard - the one voters themselves would have chosen given full information. Though this effect needn't be decisive, we estimate that the magnitude of the effect is sufficient to have affected the outcome of several presidential elections since 1980 .

Section 2 sets out to provide a set of assumptions that together are sufficient to support the majority rule mechanism. We then set that framework aside, in a sense, and generate a statistical model in Section 3 which provides an empirical indication of the claims made by epistemic democrats. Section 4 addresses potential critiques, while Section 5, finally, returns to the Propositions, lining up the theoretical conditions from Section 2 with the empirical evidence from Section 3. The formal proof of our result and technical discussion of the models are reserved for the appendix.

We recognize that it is rare to blend statistical and theoretical methods in this way. To wit, we don't intend our statistical analysis to be a decisive proof on its own, but rather as supportive given the wide extant theoretical and empirical scrutiny economic voting as received (e.g. Duch and Stevenson (2008), Lewis et al. (2009)). Though statistical models are by their nature correlational, our inferences are grounded by the rich literature that exists in the background and supports our paper's claims. These findings collectively support our point that given the electorate's desire for economic growth, their epistemic capacities advantage the better candidate.

\section{Evaluating Democracy's Truth-Tending Properties}

While there are many instances where it is difficult to determine what a community should do or which values it ought to endorse, cases of broad normative agreement leave only the facts of the matter to be contested. Consider a multidimensional decision illustrated by voters' choices in the 2012 U.S. presidential election. Along one dimension Alice and Bernice fundamentally disagree about the access women ought to have to abortions. On account of Alice's pro-life values, she is inclined to vote for Mitt Romney. Bernice, on the other hand, is pro-choice and feels strongly that President Obama should be reelected. Along another dimension, however, both Alice and Bernice agree that the government should maximize the number of Americans carrying health insurance. Given that they both endorse this same value, cashed out using the same metric, their disagreement can be construed as partly factual in kind (Page (2007): 258) which candidate will in fact lead more Americans to be insured? If Alice and Bernice are each better than random at determining the fact of the matter, we 
then have reason to think that the candidate more adept at providing healthcare (whatever the means) has his chances of winning boosted. Holding their disagreement about abortion constant, a candidate's fitness on the second dimension enhances his electability. And while the following section's empirical model has voters evaluating the economic stewardship of the incumbent against a counterfactual (rather than comparing the competing candidates directly), for purposes of clarity we will frequently discuss elections as binary contests between two opposing candidates.

In order to illustrate the plausibility of the theory we begin by formalizing wisdom of the crowd claims conducive to empirical reflection. We'll refer to this result as the 'majority rule mechanism.' Modeling votes in a two-party majoritarian election as binary random variables allows us to formally establish the link between voters' normative agreement on some element in the decision space and electoral outcomes. Assumption 1 instrumentalizes voters' agreement on the issue:

Assumption 1. Every voter is at least as-and some more-likely as otherwise to select a candidate if she believes that the candidate is superior to her rival on that issue.

The second assumption characterizes voters' competence: that their beliefs correspond to reality.

Assumption 2. Each voter is more likely to believe a candidate superior when she actually is (than when she is not).

Were this otherwise, the instrumental value of the contest would be at best null and at worst would hazard producing unwanted effects, whereby voting for a candidate $A$ in virtue of some criterion $c_{i}$ would diminish the chances that $c_{i}$ would be realized (e.g. more wide-spread healthcare in this case).

Next we specify that a candidate's superiority is relevant to her margin only insofar as it affects voters' beliefs (rather than, say, through some other indirect way). This also allows us to treat multidimensional cases, in which each issue $a_{i}$ provides its own contribution to a voter's decision.

Assumption 3. A candidate's actual superiority on some issue is only relevant to a voter's consideration insofar as it affects her beliefs about the candidate. 
Together, these three assumptions allow us to say something about how votes are cast:

Proposition 1. Under Assumptions 1, 2, and 3, a candidate's superiority to her rival on that issue increases her expected vote total.

A potential hiccup, however, is that increasing the probability of voting for a candidate doesn't necessarily increase her probability of getting elected, given certain dependencies within the electorate. If some members of the electorate cast their votes with high degrees of correlation, this entailment can be undermined. ${ }^{4}$ But a bit more ground must be covered for an increase in expected votes to reliably inhibit unwanted effects.

The simplest (if, perhaps, the strongest) additional assumption is independence:

Assumption 4. Votes are mutually independent, conditional on candidates' true superiority.

Taken together, we have the following proposition:

Proposition 2. Under Assumptions 1-4, a candidate's superiority to her rival on an issue increases her probability of being elected.

Our claim is this: in a binary election (even when the decision function is multidimensional) where independent and minimally competent voters seek to select the candidate that maximizes a shared value, the majority rule mechanism comes to recommend democracy on veritistic grounds. ${ }^{5}$

Importantly, voters need not possess epistemic access to the policy mechanisms for the election's result to have a veritistic quality - say in the case of health care, whether single-payer is superior to market-based exchanges. It need only be the case that the outcome be the intended one. And sure, a candidate's superiority on some consensus issue enhances her chances of victory, but it doesn't mean that the effect is necessarily decisive. That being said, we show in the next section that voters' beliefs about sociotropic economic conditions,

\footnotetext{
${ }^{4}$ As a simple illustration of this, consider two baseball teams. Team A scores more runs on average than Team B, but it's either feast or famine - 12 runs or none. Team B might only score 5 runs a game, compared to Team A's 6, but with lower variance they win more games, since Team A "wastes" runs when it wins. This toy example shows how the probability of victory doesn't necessarily increase with the increased probability of getting votes, given this sort of underlying dependency.

${ }^{5}$ The technical restatement of this proposition and its proof are provided in the appendix, Section 6.1.
} 
on which broad agreement exists, have consistently affected U.S. presidential election results.

Beyond taking the assumptions individually, interpreting Proposition 2 can benefit from additional consideration of possible dependences between distinct issues that influence a voter's choice. If, say, economic and environmental values were anti-correlated then it might be the case that a voter would appear to vote against her economic values in virtue of giving priority to her environmental commitments, which seems at odds with Assumption 1. In such a case, even though ceteris paribus all voters agree here that economic growth is a good, were it to come at the expense of environmental conservation it would not, all things considered, necessarily raise the probability of a candidate's vote share.

Consider a counterfactual, however: Even with such dependencies, it is still the case that the voter is more likely to vote for the anti-environmental conservation candidate in question, conditional on that candidate being better on economic policy than were that candidate anti-environmental conservation and worse than her rival on economic matters. Proposition 2 might then be recast as describing the difference in the probability of a candidate's election between a scenario in which she is superior to her rival on an issue of broad consensus, to one in which she is inferior on that same issue, holding constant her position on all other relevant issues (see Dietrich and Spiekermann (2013) for a similar argument). ${ }^{6}$

\section{The Empirical Plausibility of Democracy's Truth- Tending Properties}

The propositions above articulate epistemic considerations relevant to majoritarian voting, stipulating conditions under which a candidate's fitness on some issue increases the probability of her being elected, mediated by voters' beliefs. The practical relevance, however, hinges on whether the conditions correspond to reality. As such, we now turn to the case of sociotropic economic voting in U.S. presidential elections to demonstrate how people's beliefs mediate their votes.

\footnotetext{
${ }^{6}$ Say Assumptions 1-4 hold conditional on a set of facts $\mathcal{F}$. Then reconfigure Proposition 2 to read: If Assumptions 1, 2, and 4 hold conditional on $\mathcal{F}$, then a candidate's superiority to her rival on an issue increases her probability of being elected, conditional on $\mathcal{F}$. This conditioning strategy also weakens Assumption 4: sets of voters with common policy preferences will tend to vote similarly across elections; however, if these preferences are included in $\mathcal{F}$, their mutual independence is restored. The statement and proof of the propositions in the appendix, and implicitly in the regression model of Section 3.1, rely on $\mathcal{F}$.
} 
Though economic voting is not a part of every election (Stein (1990); Nadeau and Lewis-Beck (2001):171), U.S. presidential elections do appear to turn on economic performance (Miller and Wattenberg (1985), Fiorina (1978); Lockerbie (1992); Lanoue (1994); Lewis-Beck and Stegmaier (2000); Nadeau and LewisBeck (2001); Markus (1988)). Voters hold the president responsible for not only their own financial well-being, but also for the health of the domestic economy more broadly - referred to as "sociotropic" economic voting (Kinder and Kiewiet (1981)). Moreover, it is likely that the president has some control over macroeconomic outcomes (Blinder and Watson (2014)). Sociotropic economic voting trends reveal that people widely want the economy to grow and reflect on economic trends in order to select candidates with policies better suited to maintain growth (Duch and Stevenson (2008): 14). We look to economic voting, in part, because of the theory's robustness. Both Duch and Stevenson (2008) and Lewis et al. (2009) review this sizable literature and argue forcefully for a strong causal relationship between economic performance and people's assessment of whom to vote for president. It is this broad theoretical and empirical support for economic voting that allows us to make inferences from our models, beyond assignments of mere correlation.

While any number of criteria plausibly affect people's judgment about the economy (e.g. inflation, unemployment, trade deficits), the annual change in real disposable income $(\Delta R D I$-average income, less taxes) highlights a broad agreement that exists and informs voters' decisions for whom to vote. $\Delta R D I$ is an attractive metric not only because it corresponds to an empirical measure of economic performance, but also as people plausibly have epistemic access to it. People can look around and assess the after-tax money that they and those around them have recently earned. Voters need not diligently read the Wall Street Journal or watch CNBC to know whether the economy around them is growing or shrinking. ${ }^{7}$ As evidence for this claim, we show that RDI growth is an important predictor of individual votes, even after controlling for several canonical variables. ${ }^{8}$

\footnotetext{
${ }^{7}$ While wages have largely stagnated over the last four decades, the Congressional Budget Office shows slight growth in even the bottom quartile. Even so, since our inquiry is primarily interested in sociotropic rather than pocketbook voting, we believe that this phenomenon does not undermine the strength of our findings (Congress (2011)).

${ }^{8}$ Though $\triangle R D I$ serves as a particularly attractive metric, the results are consistent for others like GDP growth, too.
} 


\subsection{Empirical Results}

To understand the influence of macroeconomic performance on voters' beliefs and choices, we draw from Nadeau and Lewis-Beck (2001), and fit a regression model to American National Election Survey (ANES) data. ${ }^{9}$ Our models (Table 1) provide evidence that $\Delta R D I$ predicts voters' choices as mediated by their beliefs, and corroborates earlier studies which have shown that $\Delta R D I$ is a strong predictor of votes for U.S. president. ${ }^{10}$ But when the model also accounts for respondents' subjective economic beliefs (models (2)-(4)), the magnitude of $\Delta R D I$ 's coefficient diminishes to near zero and becomes statistically insignificant. In keeping with Nadeau and Lewis-Beck's account, $\Delta R D I$ 's impact on votes is mediated by a person's subjective economic beliefs. The level of $\Delta R D I$ affects subjects' perceptions of the economy, which in turn affects their voting decisions.

As in Nadeau and Lewis-Beck's model, subjective measures have a large, positive association with $\Delta R D I$. People's assessment of the national change in income appears to make up a sizable part of what the retrospective and prospective variables measure. We find that retrospective and prospective assessments of the economy are correlated with $\triangle R D I$ at a level of 0.67 and 0.16 , respectively.

This is consistent with Nadeau and Lewis-Beck's finding that when retrospective is regressed on $\Delta R D I$ the $R^{2}$ value is 0.77 and $R^{2}=0.39$ when prospective is regressed on $\triangle R D I$, indicating that people's economic beliefs indeed correspond to empirical fact (Nadeau and Lewis-Beck (2001): 161, 174). These results follow earlier findings that voters reflect on economic performance to select policies that favor growth, thereby lending support to the epistemic quality of democratic elections.

To wit, the size of the effect here is large. Were voters to assess economic progress merely at random the model indicates that the popular presidential vote would have flipped at least five elections in our dataset (1980-2016). ${ }^{11}$

\footnotetext{
${ }^{9}$ While our models rely on the substantive theory behind those in Nadeau and Lewis-Beck (2001), the fresh analysis allows us to fix some methodological concerns as well as direct attention to the specific ways in which beliefs mediate between voters' observations and decisions (votes). The technical discussion is provided in the appendix.

${ }^{10} \mathrm{An}$ increase of one in percent $\triangle R D I$ increases the odds of a respondent voting for the incumbent by a factor of about 10-32\%, adjusting for voters' perceptions of their individual financial situations, their race, their state, and their party identification, as well as the election year. This is an approximate $95 \%$ confidence interval.

${ }^{11}$ We look at the problem like this: Voters' beliefs about economic growth vary from election to election, a function of the information they possess. What if their beliefs were generated at random, however? We assess that question in two ways. First, what if instead of varying
} 


\begin{tabular}{|c|c|c|c|c|}
\hline & \multicolumn{4}{|c|}{ Dependent variable: } \\
\hline & \multicolumn{4}{|c|}{ vote } \\
\hline & $(1)$ & $(2)$ & $(3)$ & $(4)$ \\
\hline $\mathrm{RDI}$ & $\begin{array}{c}0.187^{* * *} \\
(0.046)\end{array}$ & $\begin{array}{c}0.004 \\
(0.053)\end{array}$ & $\begin{array}{l}0.159^{*} \\
(0.070)\end{array}$ & $\begin{array}{c}0.005 \\
(0.056)\end{array}$ \\
\hline finances & $\begin{array}{c}0.314^{* * *} \\
(0.029)\end{array}$ & $\begin{array}{c}0.184^{* * *} \\
(0.041)\end{array}$ & $\begin{array}{c}0.327^{* * *} \\
(0.042)\end{array}$ & $\begin{array}{c}0.188^{* * *} \\
(0.043)\end{array}$ \\
\hline incumbentParty & $\begin{array}{c}-0.491^{* * *} \\
(0.089)\end{array}$ & $\begin{array}{c}-0.482^{* * *} \\
(0.079)\end{array}$ & $\begin{array}{c}-0.368^{* * *} \\
(0.105)\end{array}$ & $\begin{array}{c}-0.468^{* * *} \\
(0.084)\end{array}$ \\
\hline retrospective & & $\begin{array}{c}1.170^{* * *} \\
(0.073)\end{array}$ & & $\begin{array}{c}1.120^{* * *} \\
(0.078)\end{array}$ \\
\hline prospective & & & $\begin{array}{c}0.414^{* * *} \\
(0.049)\end{array}$ & $\begin{array}{c}0.268^{* * *} \\
(0.051)\end{array}$ \\
\hline incumbentParty:race & $\begin{array}{c}1.180^{* * *} \\
(0.073)\end{array}$ & $\begin{array}{c}1.080^{* * *} \\
(0.088)\end{array}$ & $\begin{array}{c}1.050^{* * *} \\
(0.091)\end{array}$ & $\begin{array}{c}1.040^{* * *} \\
(0.093)\end{array}$ \\
\hline incumbentParty:partyID & $\begin{array}{c}0.861^{* * *} \\
(0.012)\end{array}$ & $\begin{array}{c}0.889^{* * *} \\
(0.016)\end{array}$ & $\begin{array}{c}0.899^{* * *} \\
(0.016)\end{array}$ & $\begin{array}{c}0.874^{* * *} \\
(0.017)\end{array}$ \\
\hline Constant & $\begin{array}{c}-0.386^{*} \\
(0.157)\end{array}$ & $\begin{array}{c}0.217 \\
(0.150)\end{array}$ & $\begin{array}{c}-0.394^{*} \\
(0.193)\end{array}$ & $\begin{array}{c}0.199 \\
(0.160)\end{array}$ \\
\hline Observations & 21,944 & 15,769 & 14,574 & 14,508 \\
\hline Log Likelihood & $-6,399.000$ & $-3,347.000$ & $-3,113.000$ & $-2,989.000$ \\
\hline Akaike Inf. Crit. & $12,814.000$ & $6,713.000$ & $6,243.000$ & $5,998.000$ \\
\hline Bayesian Inf. Crit. & $12,878.000$ & $6,782.000$ & $6,312.000$ & $6,073.000$ \\
\hline
\end{tabular}

Table 1: Results from four multilevel logistic regressions described in equation (4) in the appendix. $\Delta R D I$ is the percent change in national real disposable income per-capita from the previous year; incumbentParty is equal to 1 when Democrats are incumbent and -1 when Republicans are; finances is equal to 1 when respondents answer that their family's financial situation is better than a year ago, -1 when worse and 0 when the same; prospective is 1 when respondents answer that they expect the economy to improve in the following year, -1 when they expect it to get worse and 0 if they expect it to stay the same; retrospective is 1 when respondents answer that they believe the economy improved in the previous year, -1 when they believe it got worse and 0 if they believe it stayed the same; race is equal to 1 if the respondent is non-white and 0 if the respondent is white; partyID is a five-point scale for party identification: positive for Democrats, negative for Republicans; 3 for strong, 1 for weak or leaning, and 0 for apolitical. Models based on ANES data from presidential elections from 1956-2016 (1) or 1980-2016 (2)-(4) (as ANES only began collective data for retrospective and prospective in 1980). 


\subsection{Epistemic Heterogeneity in the Model}

The conditions of the majority rule mechanism regard individual level properties while models (1)-(4) estimate aggregate association between people's beliefs of economic progress and actual economic growth. Results in Table 1 suggest that voters as a whole are both more likely to vote for the incumbent party the higher $\triangle R D I$ (model (1)) and more likely to vote for the incumbent party when they believe the economy is growing (models (2)-(4)). This is consistent with findings from the economic voting literature that voters as a whole select the candidate they believe is more apt to sustain growth. It's conceivable, though, that a substantial portion of voters are systematically mistaken regarding economic growth, believing the economy is growing when it is shrinking and vice versa. Such voters would violate Assumption 2 and, if their number sufficient, undermine the majority rule mechanism.

While the data don't allow us to track individual competencies, we can look at subgroups within the population to assess whether any are systematically confused. Interacting $\triangle R D I$ and retrospective with a variety of respondents' demographic features (finances, party identification, race, age, class, education, gender, marital status and urbanism), no combination thereof produced a negative correlation between our two variables of interest. That is, no subgroup we looked at was systematically worse than random at knowing whether the economy was growing or shrinking. ${ }^{12}$

beliefs from year to year, voters merely stuck to the mean belief for all years? The mean is just the value that one would pull without knowing anything about the local empirical reality-a baseline or default. Were the actual values for retrospective to be swapped for the variable's mean value across all years the magnitude would have been large enough to alter the popular vote totals in 1980, 1992, 2000, 2008, and 2016. Second, what if instead of varying beliefs from year to year, voters somehow adopted beliefs one standard deviation from the mean? Since standard deviation is a measure of the expected variation from the mean, if voters' beliefs were just random they could fall anywhere, but on average within one standard deviation. In that case the magnitude of the effect would have been sufficiently large to swing the popular vote in every election retrospective was measured, namely 1980-2016. The results and corresponding code are posted online: https://tiny.cc/testingEpDemCode.

${ }^{12} \mathrm{~A}$ final minor worry is that the effect might derive from a minority of voters who want the economy to shrink as opposed to the (vast) majority that want it to grow. We try to get a handle on this by estimating the number of those who want the economy to contract by looking at the proportion of survey respondents answering that "the economy was doing much better" given a value of $\triangle R D I$ in the bottom quartile. This puts the number at $3.3 \%$ (with a $95 \%$ upper bound of $3.6 \%$ ), but that is likely a large overestimate. The fact that surveys don't even ask respondents whether they wish the economy would contract is possibly the best evidence of the ubiquity of the assumption. Given this, it is just not possible for the observed effect to be due to a minority of mistaken voters who want the economy to shrink. 


\section{Critiques}

There are, however, standing critiques of the economic voting literature. Christopher Anderson, for instance, doubts the link between economic performance and electoral outcomes (Anderson (2007): 272), particularly given the myriad of other metrics that might motivate voters' decisions (ibid.: 274). Furthermore, he along with Bryan Caplan call into question whether the information voters do have allows them to make such inferences about the economy (Anderson (2007): 279-281; Caplan (2006): chapter 3).

We needn't suppose that most voters directly observe $\Delta R D I$ in order for them to care about its performance, though. $\Delta R D I$ might well serve as a proxy for voters observations of local and national economic trends. For instance, percent change in $\Delta R D I$ is correlated with percent change in GDP $(\rho=0.71)$ and inversely correlated with the change in unemployment $(\rho=-0.43) .{ }^{13}$ Yet $\triangle R D I$ is also something that voters can plausibly look around and observeAre those I see taking home more or less pay than in the past? Have their consumer habits changed? Are they tightening their belts? This contention is consistent with our finding that $\triangle S D I$ (state-level real disposable income) also has a marginally significant effect (at a 10\% level) on presidential vote share, loosely suggesting that people make political inferences using both national and regional economic signals (though the former is clearly more pronounced). But we also have good theoretical reasons to think that voters have access to rich empirical knowledge. Arthur Lupia and others have written that voters can keyin to sophisticated information using proxies and shortcuts which allow them to make refined decisions (Kinder and Kiewiet (1981): 130-1; Lupia and McCubbins (2000); Lupia (2006)). And while Bartels (1996) shows that uninformed voters are different from their informed peers, he does not directly contest our finding here that voters are dispositionally better than random (at least at assessing economic growth).

Meanwhile Caplan's strongest counterexamples indicate that voters are woefully ignorant about economic mechanisms such as whether "technology is displacing workers" (Caplan (2006): 65). As mentioned above, however, it is not necessary for voters to have access to the causal mechanisms that produce some outcome for elections to be thought veritistic. Whether RDI is growing at a normal clip regards performance rather than process, which economists and layvoters both do a fairly good job of assessing (Caplan (2006): 78). Whether

\footnotetext{
${ }^{13}$ Data Source: FRED, Federal Reserve Economic Data, Federal Reserve Bank of St. Louis: http://research.stlouisfed.org/fred2/graph/?g=DQL accessed 06/10/2019. Estimates are based on monthly data from 1960-2016.
} 
take-home income has risen or fallen is something that people realistically have access to. The steady growth in RDI from years 1959 to the present, and the correlation of 0.81 between successive year's deviation from that trend, indicate a rather low epistemic burden to predicting growth for the coming year. Just knowing the previous year's RDI provides a good deal of predictive power absent any sophisticated training. Indeed, even Achen and Bartels (2016), who are not kind to epistemic interpretations of democracy, carve out an exception for economic voting (ibid.: 97-8). Given this, we believe that it is perfectly plausible that voters have the requisite information and capacity to incorporate the fact of economic growth into their decision of whom to vote for.

\section{Discussion}

When epistemic democrats argue that wisdom of the crowd results, such as the Condorcet Jury Theorem or Miracle of Aggregation, pertain to politics they do so assuming there exist cases which track the models' assumptions. We point out that such instrumental claims are weak absent a compelling empirical example. This paper empirically tests the claims of epistemic democrats while responding to skeptics such as Anderson (2006), Ingham (2013), and Urbinati (2014) who argue that we can't possibly think about elections having veritistic results, since voters are disagreeing on matters of value, not fact. We bracket that worry by focusing attention on a dimension of the vote on which there exists practical consensus, leaving the facts to be contested. We show that, given independent and minimally competent voters, a majority rule mechanism can be understood to bias an election in favor of the better candidate, non-trivial given that most decisions entail a bundle of considerations.

The case of sociotropic economic voting in U.S. presidential elections offers an instance where a widely held value significantly and substantially affects an election's outcome, thereby plausibly meeting the formal conditions of Proposition 2. In this binary contest, the data indicate that voters evaluate the incumbent party with an eye to the annual change in real disposable income, among other considerations. The broad agreement here comes to recommend the election's result by nudging the outcome in favor of the alternative voters themselves would have chosen given full information. What's more, it provides

evidence that people's votes are conditioned by epistemic means - that the effect of economic growth on electoral outcomes is mediated by people's beliefs on how the economy is fairing. Indeed we estimate that absent this effect between three and eight elections since 1980 might well have been different (as far as the 
popular vote, anyway).

To examine the plausibility of these claims we offer a series of linear regressions to model voters' decisions in U.S. presidential elections. Here voters observe national economic conditions, which inform their beliefs about the economy's performance. Those beliefs, in turn, affect their choices. The coefficient on $\Delta R D I$ is substantial and significant only when economic beliefs are excluded from the model. Once included, the subjective measures soak up its explanatory role, illustrating the role of beliefs in affecting political outcomes. Voters who believe that the economy has grown or will grow are more likely to vote for the incumbent party. And insofar as voters value economic growth, this majority rule mechanism operates to inhibit unwanted effects (where voters would be less likely to obtain the outcome they value in virtue of voting for it).

Holding all other aspects of the vote constant, the majority rule mechanism, articulated by Propositions 1 and 2, formally captures how voters can be thought accurate with respect to a particular dimension of the vote. Assumption 1, that voters are as good or better than random at selecting the candidate they take to be superior, is tricky to substantiate with direct observational evidence. Our subgroup analysis, however, goes some distance to allay worries, as we fail to find any subgroup for which $\Delta R D I$ and the variable retrospective are anti-correlated.

Section 3.1 directly grounds Assumptions 2 and 3, that voters are as or more likely than random to select a candidate they believe to be better on the issue, and that these beliefs are what affect vote casting. Model (1) finds a positive association between economic performance, captured by the variable $\Delta R D I$, and votes for the incumbent. When subjective sociotropic measures are included in the regression, as in models $(2)-(4)$ the objective measure $(\Delta R D I)$ takes a near-0 coefficient, leading us to conclude that economic policy primarily figures into individual votes by way of their subjective beliefs, thereby illustrating the epistemic valence to democracy. Controlling for Party-ID and an individual's finances, the vote comes to select candidates with policies that promote widespread economic growth.

Last, Assumption 4 is a simplifying condition primarily intended to streamline the proof. Indeed we know that votes are not cast independently (e.g. Sinclair (2012)), though it is hard to know the size of the effect of dependence. We put forward what can be considered the least complicated assumption and leave it to future work to identify circumstances where dependent voting would undermine our results. It is unlikely that our findings disappear given small amounts of dependence. And as Dietrich and List (2004) points out, independence is most plausible when we have reason to think that voters are encounter- 
ing heterogeneous information, as would be the case in a nationwide presidential election with comparably high turnout. ${ }^{14}$ Propositions 1 and 2 outline common assumptions to gain traction on how democracy can leverage the wisdom of the crowd and facilitate matching the theory's correspondence to data.

Beyond supporting claims made by epistemic democrats, this paper shows the purchase of testing theoretical conjectures against empirical data. Whenever we make instrumental claims in politics, we do so conditional on certain states of the world being the case. More needs to be done to determine that empirical conditions are indeed satisfied if we are to give proper weight to these arguments. We hope to have offered one such effort here.

\section{Author Bios}

William J. Berger is a Fellow with the Philosophy, Politics \& Economics Program at the University of Pennsylvania. His research looks at political epistemology in various forms, attending to matters like affective trust, polarization, and inequality.

Adam Sales is the director of SMARTER Consulting at the University of Texas College of Education. The bulk of his research pertains to the efficacy of educational interventions, with methodological interests in causal inference, regression discontinuity, and principle stratification.

\section{Acknowledgements}

The authors would like to acknowledge the editors of this journal for their careful stewardship of the paper, as well as the reviewers along the way who have helped us greatly refine it. Special thanks goes to Hélène Landemore, William English, Scott Page, Dan Singer, Patrick Grim, John Jackson, Alton Worthington, and Bob Goodin, whose meticulous feedback allowed this project to come to fruition.

\footnotetext{
${ }^{14}$ Indeed, Dietrich and Spiekermann (2013) doubles down on this line of critique. Our application of independence avoids their worries in two ways, however. First, the motivation for their critique lies in CJT's asymptotic property, absent from our majority rule mechanism. Second, they are concerned for probabilistic dependence in virtue of citizen's common evidential support for their votes. However the account that our findings support is that voters each look around and judge the health of the economy from their own observations - a contention supported by the correlation between state-level real disposable income growth and votes. In our model voters are not backing out $\triangle R D I$ from a (common) proxy, rather each directly observes the data for themselves, that is whether they and those around them have greater take-home pay than in the past.
} 


\section{Appendix}

\subsection{Proof of the Propositions}

We are interested in the electability of a particular candidate in a binary election. Let $E=1$ if she is elected, and 0 otherwise. Let $i=1,2,3, \ldots \in \mathcal{E}$ denote voters in the electorate. Let $V_{i}=1$ if voter $i$ votes for the candidate, and 0 otherwise. Say $E=1$ if and only if the proportion of votes for a candidate from $\mathcal{E}$ exceeds a threshold $\alpha$, typically $1 / 2$. In other words,

$$
E=1 \text { iff } \sum_{i \in \mathcal{E}} V_{i}>n \alpha
$$

where $n=|\mathcal{E}|$, the number of voters in $\mathcal{E}$. Let $a_{x}=1$ denote the truth of a fact $x$ that sways voters to vote for the candidate (for instance, she is better than her rival at increasing RDI). For clarity, we will drop the $x$ subscript, so $a=1$ denotes $a_{x}=1$. Let $A_{i}=1$ if voter $i$ believes $a$. Finally, let $\mathcal{F}$ be a (possibly empty) set of conditioning facts, as discussed in Footnote 4.

Then consider the following assumptions:

For all $i \in \mathcal{E}$ :

$1 \operatorname{Pr}\left(V_{i}=1 \mid A_{i}=1, \mathcal{F}\right) \geq \operatorname{Pr}\left(V_{i}=1 \mid A_{i}=0, \mathcal{F}\right)$; stated otherwise, $i$ is more likely to vote for the candidate if $i$ believes that $a=1$ than if $i$ believes that $a=0$.

$2 \operatorname{Pr}\left(A_{i}=1 \mid a=1, \mathcal{F}\right) \geq \operatorname{Pr}\left(A_{i}=1 \mid a=0, \mathcal{F}\right)$; stated otherwise, $i$ is more likely to believe that $a=1$ if indeed $a=1$ than if $a=0$.

$3 \operatorname{Pr}\left(V_{i}=1 \mid A_{i}, a, \mathcal{F}\right)=\operatorname{Pr}\left(V_{i}=1 \mid A_{i}, \mathcal{F}\right)$

4 For all $j \neq i, V_{i} \Perp V_{j} \mid a, \mathcal{F}$

Finally, the inequalities in both 1 and 2 must be strict for some non-empty subset of $\mathcal{E}$.

If Assumptions 1, 2, and 3 hold, then

$$
\mathbf{E}\left[\sum_{i \in \mathcal{E}} V_{i} \mid a=1, \mathcal{F}\right]>\mathbf{E}\left[\sum_{i \in \mathcal{E}} V_{i} \mid a=0, \mathcal{F}\right]
$$

If Assumption 4 also holds, then

$$
\operatorname{Pr}(E=1 \mid a=1, \mathcal{F})>\operatorname{Pr}(E=1 \mid a=0, \mathcal{F})
$$


When $\mathcal{F}$ is not empty, these are equivalent to a generalization of Propositions 1 and 2 .

Proof. Under Assumptions 1, 2, and 3 we have (letting all probabilities be conditional on $\mathcal{F}$ )

$$
\begin{aligned}
& \operatorname{Pr}\left(V_{i}=1 \mid a=1\right) \\
= & \mathbf{E} \operatorname{Pr}\left(V_{i}=1 \mid a=1, A_{i}\right) \\
= & \operatorname{Pr}\left(V_{i}=1 \mid A_{i}=1\right) \operatorname{Pr}\left(A_{i}=1 \mid a=1\right)+\operatorname{Pr}\left(V_{i}=1 \mid A_{i}=0\right) \operatorname{Pr}\left(A_{i}=0 \mid a=1\right) \\
= & \operatorname{Pr}\left(A_{i}=1 \mid a=1\right)\left\{\operatorname{Pr}\left(V_{i}=1 \mid A_{i}=1\right)-\operatorname{Pr}\left(V_{i}=1 \mid A_{i}=0\right)\right\}+\operatorname{Pr}\left(V_{i}=1 \mid A_{i}=0\right) \\
\geq & \operatorname{Pr}\left(A_{i}=1 \mid a=0\right)\left\{\operatorname{Pr}\left(V_{i}=1 \mid A_{i}=1\right)-\operatorname{Pr}\left(V_{i}=1 \mid A_{i}=0\right)\right\}+\operatorname{Pr}\left(V_{i}=1 \mid A_{i}=0\right) \\
= & \operatorname{Pr}\left(V_{i}=1 \mid A_{i}=1\right) \operatorname{Pr}\left(A_{i}=1 \mid a=0\right)+\operatorname{Pr}\left(V_{i}=1 \mid A_{i}=0\right) \operatorname{Pr}\left(A_{i}=0 \mid a=0\right) \\
= & \operatorname{Pr}\left(V_{i}=1 \mid a=0\right)
\end{aligned}
$$

Where the inequality is a result of Assumptions 1 and 2, and is a strict $>$ for some members of the population. Then

$$
\begin{aligned}
\mathbf{E}\left[\sum_{i \in \mathcal{E}} V_{i} \mid a=1\right]= & \sum_{i \in \mathcal{E}} \operatorname{Pr}\left(V_{i}=1 \mid a=1\right)> \\
& \sum_{i \in \mathcal{E}} \operatorname{Pr}\left(V_{i}=1 \mid a=0\right)=\mathbf{E}\left[\sum_{i \in \mathcal{E}} V_{i} \mid a=0\right]
\end{aligned}
$$

proving (2).

$V_{i} \mid a=1$ is stochastically greater that $V_{i} \mid a=0$. Therefore, under Assumption 4, $\sum_{i=1}^{n} V_{i} \mid a=1$ is stochastically greater than $\sum_{i=1}^{n} V_{i} \mid a=0$ (Shaked and Shanthikumar, 2007). Therefore, $\operatorname{Pr}(E=1 \mid a=1)=\operatorname{Pr}\left(\sum_{i=1}^{n} V_{i}>n \alpha \mid a=\right.$ 1) $>\operatorname{Pr}\left(\sum_{i=1}^{n} V_{i}>n \alpha \mid a=0\right)=\operatorname{Pr}(E=1 \mid a=0)$, as in (3) above.

\subsection{A Comparison with CJT}

The propositions described informally in Section 2 and formally in this appendix build on prior theoretical work in epistemic democracy, perhaps most famously the Condorcet Jury Theorem (CJT). In this section we will argue that our proposition may be thought of as a generalization of the CJT to the multidimensional case.

The CJT may be stated as follows (e.g. Boland, 1989):

Proposition (CJT). A decision-making body is comprised of $n \geq 3$ voters who cast votes $V_{i}, \ldots, V_{n} \in\{0,1\}$. The group's decision $E=1$ if and only if 
$\sum_{i} V_{i}>n / 2$ and $E=0$ otherwise. There is a unique correct decision $a \in\{0,1\}$; we denote each voter's belief about a as $A_{i} \in\{0,1\}$. If:

1. $V_{i}=1$ if and only if $A_{i}=1$ (Veriticity)

2. $\operatorname{Pr}\left(A_{i}=a \mid a\right)=p>1 / 2$ for all $i$ (Competence)

3. $V_{i} \Perp V_{j} \mid a, i \neq j$ (Independence)

Then $\operatorname{Pr}(E=a \mid a)>p$ and $\operatorname{Pr}(E=a \mid a) \rightarrow 1$ as $n \rightarrow \infty$

Our proposition extends the CJT to a setting in which voters' decision functions are (potentially) multidimensional, but in which there is universal consensus regarding one of those dimensions. ${ }^{15}$ This consensus dimension is analogous to the "unique correct decision" in the CJT, and we denote both by $a$. By Assumption 1 in both our proposition and the CJT, decisors cast their votes as a function of their beliefs about $a$. However, in the CJT, voters' beliefs about $a$ determine their votes entirely, whereas in a multidimensional election $a$ only affects the probability of a vote, allowing for the influence of other factors.

Likewise, Assumption 2 in our proposition is a strictly weaker version of the Competence Assumption in the CJT. In place of the CJT Assumption 2 that voters are more likely to pick the correct alternative, we assume that a fact's veriticity makes voters more likely to believe it. For example, say $a=1$, but (perhaps due to some prejudice or confusion) voter $i$ is unlikely to believe $a=1$ under most any circumstances, so $\operatorname{Pr}\left(A_{i}=1 \mid a=1\right)<1 / 2$, violating the CJT Competence Assumption. However, if the probability that $i$ believes that $a=1$ when it's true is still greater than when it's false, $\operatorname{Pr}\left(A_{i}=1 \mid a=\right.$ 1) $>\operatorname{Pr}\left(A_{i}=1 \mid a=0\right)$, our Assumption 2 is satisfied. Conversely, the CJT Competence Assumption implies that $\operatorname{Pr}\left(A_{i}=1 \mid a=1\right)>1 / 2>\operatorname{Pr}\left(A_{i}=\right.$ $1 \mid a=0)$, so our Assumption 2 is strictly weaker.

That said, Dietrich (2008) shows that for CJT to hold, we must merely have $\bar{p}=\sum_{i} p_{i} / n>1 / 2 .{ }^{16}$ This assumption is neither strictly weaker nor stronger than ours. On the one hand, if, say, as above $\operatorname{Pr}\left(A_{i}=1 \mid a=1\right)=0.02$ and $\operatorname{Pr}\left(A_{i}=1 \mid a=0\right)=0.01$, but this time for all voters $i$, our assumption would be satisfied, but Dietrich (2008) would not. On the other hand, it is possible for some subset of the electorate to violate our assumption but be outweighed by the remainder of the electorate, so $\bar{p}>1 / 2$. In any event, simply substituting

\footnotetext{
${ }^{15}$ Dietrich and Spiekermann (2013) only articulate assumptions $2 \& 3$ for CJT. We add assumption 1 to preserve a rough correspondence with the paper's majority rule result.

${ }^{16}$ Boland (1989) shows that for $\operatorname{Pr}(E=a \mid a)>\bar{p}$ to hold in finite samples, we must assume $\bar{p}>1 / 2+1 / 2 n$.
} 
$\bar{p}>1 / 2$ into our proposition would not suffice, since a small group of mistaken voters might undermine the result if they assign particularly high weight to the issue.

Our results, Propositions 1 and 2 in section 6.1, are weaker than the CJT as well - indeed, they ought to be. If broad agreement holds for only one of many issues in an election, it would be troubling to state that $\operatorname{Pr}(E=1 \mid a=1) \rightarrow 1$ as the electorate grows, implying that all other issues - legitimate, if ambiguousbecome irrelevant. Instead, as in the case with belief, we merely show that a candidate's superiority on the issue increases her probability of being elected, relative to what it would have been had she instead been inferior. That is, we claim that superiority on an agreed-upon issue boosts a candidate's chances, but provides no guarantees.

Additionally, unlike the CJT, our result holds for finite samples.

Finally, our independence assumption is the same as CJT's. This suggests that relaxations of independence in the CJT case (e.g. Boland et al. (1989)) may work in our case as well.

\subsection{Statistical Models: Methodological Details}

The models in Section 3.1 are multilevel/hierarchical logistic regressions (Raudenbush and Bryk, 2002, e.g.). Let $V_{i}=1$ if $i$ votes for the candidate representing the incumbent party, and $V_{i}=0$ otherwise. Then model (1) is:

$$
\begin{aligned}
\operatorname{Pr}\left(V_{i, \text { elec }}=1\right)= & \text { logit }^{-1}\left(\alpha+\beta_{1} R D I_{\text {elec }}+\beta_{2} \text { Finances }_{i, \text { elec }}\right. \\
& +\beta_{3} \text { IncumbentParty }_{\text {elec }}+\beta_{4} \text { PartyI }_{i, \text { elec }}+\beta_{5} \text { Race }_{i, \text { elec }} \\
& \left.+\nu_{\text {elec }}+\eta_{\text {state }[i]}\right)
\end{aligned}
$$

Here, $\operatorname{logit}^{-1}(\cdot)$ denotes the inverse logit function, so $\operatorname{logit}^{-1}(x)=e^{x} /(1+$ $\left.e^{x}\right) . R D I_{\text {elec }}$ is the percent change in RDI per capita from the previous year, Finances $_{i, \text { elec }}$ is an individual's assessment of his own personal finances, compared to the previous year (1 denotes "better," 0 "the same," -1 "worse"). IncumbentParty elec $_{\text {codes }}$ whether the Democratic or Republican party was the incumbent in the election. PartyI $D_{i, \text { elec }}$ is a five-point scale that codes to what extent the voter's party identification agrees with the incumbent party (3: strongly agrees, 2 : weakly agrees, 0 : indifferent, -2 weakly disagrees, -3 : strongly disagrees) and Race $_{i, e l e c}$ is an indicator for race, also aligned with incumbent party (if the incumbent party is Republican, 1 indicates 'white' and 0 'nonwhite,' with the opposite if the incumbent party is Democratic). $\nu_{\text {elec }}$ 
and $\eta_{\text {state }[i]}$ are random intercepts for election year and $i$ 's state of residence, modeled as normally distributed with mean zero. The parameters $\alpha$ and $\beta_{k}$, $k=1, \ldots, 5$ and the standard deviations of $\nu$ and $\eta$ are estimated from the data.

Models (2)-(4) additionally include voter-level retrospective and/or prospective sociotropic measures. The "retrospective" measure is a voter's answer to the question: "Would you say that over the past year the nation's economy has gotten better, stayed (all yrs. exc 1984: about) the same or gotten worse?" while the "prospective" measure is a voter's answer to the question: "Do you expect the economy to get better, get worse, or stay about the same?" (1: better, -1 : worse, 0: same).

Model (1) draws from American National Election Survey (ANES) time series Studies (2018) data on presidential voting from 1956-2016. Models (2)(4), which include sociotropic variables, are fit to data from presidential elections from 1980-2016, since the ANES only began measuring individual's beliefs of sociotropic economic performance following the 1976 election. RDI data is from the National Bureau of Economic Research. The models were fit using the lme4 package in $\mathrm{R}$ (Bates et al., 2014). Replication code can be found online at https://tiny.cc/testingEpDemCode.

For the sake of simplicity, the results in Table 1 came from a "complete case analysis" of the data, which dropped any case with any missing regressors. However, in a supplemental analysis we accounted for item-level nonresponse with multiple imputation (Rubin, 2004), using the $\mathrm{R}$ package mice (van $\mathrm{Bu}-$ uren and Groothuis-Oudshoorn, 2011). This relaxes the strong assumption that item-level nonresponse is entirely random, replacing it with an assumption that nonresponse is random after accounting for the observed regressors. The results were very similar to those in Table 1.

A final caveat is that, though ANES is a nationally representative survey, our coefficient estimates are design consistent for the subjects in the study who voted or reported their votes. Due to the difficulty of fitting a multilevel model with survey weights (Gelman, 2007), we fit an unweighted model, which limits the external validity of its estimates. That being said, our attempts to fit weighted models in Stata (StataCorp, 2013) with the gllamm function (Rabe-Hesketh et al., 2004) yielded broadly similar results.

\subsubsection{Differences from Nadeau and Lewis-Beck (2001)}

Model (4) draws heavily on the main models presented in Nadeau and LewisBeck (2001, NLB). In particular, the set of predictors and interactions was taken directly from their models. On the other hand, our model differed from their's 
in several respects.

First, whereas NLB used ordinary least squares (OLS) to model votes as a linear function of the predictors, we used a logistic model, which is a more common choice for modeling dichotomous outcomes such as votes. The advantages and disadvantages of "linear probability models" such as NLB's, as compared to logistic models, are the subject of a long-running debate in econometrics and statistics which is beyond the scope of this paper. That said, there is broad agreement that OLS standard errors - and hence p-values and confidence intervals - are inappropriate for modeling dichotomous outcomes without further adjustment (Agresti, 2002, sec. 4.6). Furthermore, we found that OLS fit election data particularly poorly, with more than $10 \%$ of fitted values falling outside of the $0-1$ probability range.

Second, the NLB model does not account for clustering of votes by election, and instead treated the main variable of interest, $\Delta R D I$, as an individual-level variable. This has the effect of artificially decreasing standard error estimates and producing over-optimistic inference. We account for this clustering by including random intercepts for election year. We also included state random effects to account for state-level idiosyncrasies that are stable over time. ${ }^{17}$

We further expanded on NLB's model in two different ways. First, the model in NLB was fit using years 1956-1996, which we extended through 2016, using, in part, the ANES 2016 time-series file Studies (2018). We chose to use individual-level data post-1976 because our scientific question fundamentally regards individual voting decisions as a function of their beliefs. As such we gain substantive purchase on our research question by omitting these aggregate level data and restricting our attention to those years where the variables "retrospective" and "prospective" were captured. By including four more presidential elections than Nadeau and Lewis-Beck (2001), those from 2000-2016, we could also mitigate the consequences of omitting elections from 1956-1976. Second, while their model used an aggregate sociotropic metric for economic voting, we included individual-levels where possible, which conveniently allows us to skirt any worries associated with the ecological fallacy.

\subsubsection{Modeling Heterogeneity}

Since each wave of the ANES survey selects a different set of voters, the ANES data don't allow us to identify the individuals who systematically misjudge the economy, and thereby directly rule out such a possibility. However, the

\footnotetext{
${ }^{17}$ An alternative approach is to use cluster-robust standard errors. Doing so, in our model, gave broadly similar results.
} 
ANES data do allow us to identify the correlations between $\triangle R D I$ and voters' perceptions of the economy within demographic sub-groups. A demographic whose members' retrospective judgment of the economy correlate negatively with $\triangle R D I$ may indicate a problem. To attempt to identify such a sub-group, we fit a multilevel linear model to the data, predicting retrospective as a function of $\Delta R D I$. The model included interactions between $\Delta R D I$ and a thick set of probative variables including personal finances, incumbent party, race, and party ID (variables incorporated in models (1)-(4)), in addition to social class, education, gender, Hispanic identification, marital status, urbanism, and state. This test seeks to find exceptional cases, subsets of the population that systematically misjudge the health of the economy. Though it is large, we needn't worry that the model is overfit, since the setup here is meant to serve as a conservative test, identifying subgroups that could challenge our conjecture. The estimated slope of the relationship between retrospective and $\Delta R D I$ for each survey respondent is the sum of the $\Delta R D I$ main effect and the interaction coefficients corresponding to that respondent's demographic information. Calculated thusly, no respondent's estimated slope was negative - for every subgroup we identified, higher $\Delta R D I$ was associated with higher retrospective judgments of the economy.

To test the possible heterogeneity of values held among the electorate we estimate the conceivable size of such a minority that might unwittingly vote for the right candidate given mistaken beliefs by asking whether there exists some subset of the sample that prefers a shrinking economy. To do this we fit another large interaction model: this time, a multilevel logit model predicting votes as a function of $\triangle R D I$ interacted with all of the same probative covariates as above. Again, no respondent's estimated $\triangle R D I$ slope was negative - for every subgroup we identified, higher $\Delta R D I$ was associated with a higher probability of voting for the incumbent.

Replication code and results for these two models can be found at https: //tiny.cc/testingEpDemCode.

\section{References}

Achen, Christopher H and Bartels, Larry M. 2016. Democracy for Realists:

Why Elections Do Not Produce Responsive Government. Princeton University Press.

Agresti, Alan. 2002. Categorical Data Analysis, volume 359. John Wiley \& Sons. 
Anderson, Christopher J. 2007. "The End of Economic Voting? Contingency Dilemmas and the Limits of Democratic Accountability." Annual Review of Political Science 10:271-296.

Anderson, Elizabeth. 2006. "The Epistemology of Democracy." Episteme 3:8-22.

Bartels, Larry M. 1996. "Uninformed Votes: Information Effects in Presidential Elections." American Journal of Political Science 194-230.

Bates, Douglas, Maechler, Martin, Bolker, Ben, and Walker, Steven. 2014. lme4: Linear Mixed-Effects Models Using Eigen and S4. R package version 1.1-6.

Blinder, Alan S and Watson, Mark W. 2014. "Presidents and the US Economy: An Econometric Exploration." Technical report, National Bureau of Economic Research.

Boland, Philip J. 1989. "Majority Systems and the Condorcet Jury Theorem." The Statistician 181-189.

Boland, Philip J, Proschan, Frank, and Tong, Yung Liang. 1989. "Modelling Dependence in Simple and Indirect Majority Systems." Journal of Applied Probability 26:81-88.

Caplan, Bryan. 2006. The Myth of the Rational Voter. Princeton University Press.

Congress, US. 2011. "Trends in the Distribution of Household Income between 1979 and 2007." Congressional Budget Office.

Dietrich, Franz. 2008. "The Premises of Condorcet's Jury Theorem are Not Simultaneously Justified." Episteme 5:56-73.

Dietrich, Franz and List, Christain. 2004. "A Model of Jury Decisions Where All Jurors Have the Same Evidence." Synthese 142:175-202.

Dietrich, Franz and Spiekermann, Kai. 2013. "Epistemic Democracy with Defensible Premises." Economics \& Philosophy 29:87-120.

Duch, Raymond M. and Stevenson, Randolph T. 2008. The Economic Vote: How Political and Economic Institutions Condition Election Results. Cambridge University Press.

Fiorina, Morris P. 1978. "Economic Retrospective Voting in American National Elections: A Micro-Analysis." American Journal of Political Science 426-443. 
Gelman, Andrew. 2007. "Struggles with Survey Weighting and Regression Modeling." Statistical Science 22:153-164.

Goldman, Alvin I. 1999. Knowledge in a Social World. Oxford University Press.

Ingham, Sean. 2013. "Disagreement and Epistemic Arguments for Democracy." Politics, Philosophy, and Economics 12:136-155.

Kinder, Donald R. and Kiewiet, D. Roderick. 1981. "Sociotropic Politics: The American Case." British Journal of Political Science 11:129-161.

Landemore, Helene. 2013. Democratic Reason: Politics, Collective Intelligence, and the Rule of Many. Princeton University Press.

Lanoue, David J. 1994. "Retrospective and Prospective Voting in PresidentialYear Elections." Political Research Quarterly 47:193-205.

Lewis, Michael S., Jacoby, William G., Norpoth, Helmut, and Weisberg, Herbert F. 2009. The American Voter Revisited. University of Michigan Press.

Lewis-Beck, Michael S and Stegmaier, Mary. 2000. "Economic Determinants of Electoral Outcomes." Annual Review of Political Science 3:183-219.

List, Christain and Goodin, Robert E. 2001. "Epistemic Democracy: Generalizing the Condorcet Jury Theorem." Journal of Political Philosophy 277-306.

Lockerbie, Brad. 1992. "Prospective Voting in Presidential Elections, 1956-1988." American Politics Research 20:308-325.

Lupia, Arthur. 2006. "How Elitism Undermines the Study of Voter Competence." Critical Review 18:217-232.

Lupia, Arthur and McCubbins, Matthew D. 2000. "The Institutional Foundation of Political Competence: How Citizens Learn What They Need to Know." In Elements of Reason. Cambridge Univ Press.

Markus, Gregory B. 1988. "The Impact of Personal and National Economic Conditions on the Presidential Vote: A Pooled Cross-Sectional Analysis." American Journal of Political Science 137-154.

Miller, Arthur H and Wattenberg, Martin P. 1985. "Throwing the Rascals Out: Policy and Performance Evaluations of Presidential Candidates, 1952-1980." American Political Science Review 79:359-372. 
Nadeau, Richard and Lewis-Beck, Michael S. 2001. "National Economic Voting in US Presidential Elections." Journal of Politics 63:159-181.

Page, Scott. 2007. The Difference: How the Power of Diversity Creates Better Groups, Firms, Schools, and Societies. Princeton University Press.

Rabe-Hesketh, Sophia, Skrondal, Anders, and Pickles, Andrew. 2004. "GLLAMM Manual." U.C. Berkeley Division of Biostatistics Working Paper Series. Working Paper 160.

Raudenbush, Stephen W and Bryk, Anthony S. 2002. Hierarchical Linear Models: Applications and Data Analysis Methods, volume 1. SAGE Publications, Incorporated.

Rehfeld, Andrew. 2010. "Offensive Political Theory." Perspectives on Politics 8:465-486.

Rubin, Donald B. 2004. Multiple Imputation for Nonresponse in Surveys, volume 81. John Wiley \& Sons.

Schwartzberg, Melissa. 2015. "Epistemic Democracy and Its Challenges." Annual Review of Political Science 18.

Shaked, Moshe and Shanthikumar, J George. 2007. Stochastic Orders. Springer.

Sinclair, Betsy. 2012. The Social Citizen. Chicago: University of Chicago Press.

StataCorp. 2013. "Stata Statistical Software: Release 13."

Stein, Robert M. 1990. "Economic Voting for Governor and US Senator: the Electoral Consequences of Federalism." The Journal of Politics 52:29-53.

Studies, The American National Election. 2018. "ANES Time Series Cumulative Data File (1948-2016) [dataset]."

Surowiecki, James. 2004. The Wisdom of the Crowds. Doubleday.

Urbinati, Nadia. 2014. Democracy Disfigured. Harvard University Press.

van Buuren, Stef and Groothuis-Oudshoorn, Karin. 2011. "mice: Multivariate Imputation by Chained Equations in R." Journal of Statistical Software 45:167.

Wiens, David. 2015. "Against Ideal Guidance." The Journal of Politics 77:433446. 